\title{
ARTE E CULTURA DE MASSA EM A GRANDE VIAGEM, DE MIRNA PINSKY ${ }^{1}$
}

\author{
Pâmela Rodrigues Scutari²
}

Resumo: Este artigo aborda os aspectos literários e de cultura de massa do livro infantojuvenil $A$ Grande Viagem (2006), de Mirna Pinsky, que retrata os desafios de Marcelo e Mercedes em meio às drogas e a falta de autoestima por meio de três vozes narrativas - portanto, linguagens diversas -, não linearidade e referências literárias e culturais. Com fundamentos teóricos de Borelli (1996), Ceccantini $(2006,2011)$, Eco $(1985,2001)$ e Lajolo (2002), os quais possibilitam reflexão sobre a literatura de entretenimento em relação à indústria cultural e o cânone, e a função do mediador de leitura, constata-se, assim, que a obra de Pinsky oferece ao leitor nova perspectiva quanto à realidade das personagens e o mundo que os cerca, e, embora inserida no circuito mercadológico, pode assumir natureza literária.

Palavras-chave: Literatura infantojuvenil. Recepção literária. Indústria cultural.

\section{Introdução}

Mirna Silva Gleich (São Paulo, 12 de dezembro de 1943), conhecida pelo pseudônimo Mirna Pinsky, é graduada em jornalismo pela Faculdade de Jornalismo Cásper Líbero, e pós-graduada e mestre em Teoria Literária pela Universidade de São Paulo (USP). Por muitos anos, trabalhou como repórter e redatora de jornais e revistas; porém, destaca-se por sua carreira literária, que teve início como poeta e dramaturga. Em 1978, publicou seu primeiro livro infantil, Zero Zero Alpiste (Formato, 1978), e, a partir de 1980, dedicou-se, exclusivamente, à área editorial. Autora de quarenta e oito livros publicados - três deles, no exterior -, somando em 3,8 milhões de exemplares vendidos, Pinsky recebeu, dentre prêmios e menções honrosas, dois Jabutis ${ }^{3}$ da Câmara Brasileira do Livro e o Prêmio da Academia Brasileira de Letras de Literatura Infantojuvenil ${ }^{4}$. Desde 2002 e 2004, a escritora desenvolve os projetos sociais Escreva Comigo e Ler com Prazer, respectivamente, estimulando o contato dos alunos com os livros e a alfabetização em escolas de rede estadual. Nesse sentido, seu empenho em Ihes apresentar a leitura como

\footnotetext{
10 presente artigo foi parcial e anteriormente publicado no site Mirna Pinsky. Disponível em: <http://mirnapinsky.com.br/sobre-a-grande-viagem/>. Acesso em: 8 ago. 2018.

2 Mestranda em Estudos Literários pelo Programa de Pós-Graduação em Letras do Instituto de Biociências, Letras e Ciências Exatas de São José do Rio Preto (Unesp).

${ }^{3}$ As Muitas Mães de Ariel (Atual Editora, 1980), na categoria Literatura Infantil, em 1981; Carta Errante / Avó Atrapalhada / Menina Aniversariante (FTD, 1999), na categoria Livro Infantil ou Juvenil, em 1995.

${ }^{4}$ Um menino, sua amiga, um fichário e dois preás (FTD, 2013), em 2014.
}

Revista de Letras JUÇARA, Caxias - Maranhão, v. 03, n. 01, p. 51 - 64, ago. $2019 \mid 51$ 
"ampliação do mundo" (PINSKY, 2009, n.p.) estaria presente, também, durante o processo de criação por que passam suas obras, abordando temas como bullying (De cabeça baixa, Atual Editora, 2014), leitura (Um menino, sua amiga, um fichário e dois preás, FTD, 2013), problemas familiares e drogas ( $A$ grande viagem, Mercuryo Jovem, 2006), relações amorosas e meio ambiente (Tão longe, tão perto, FTD, 2004) e preconceito racial (Nó na garganta, Atual Editora, 1980).

Este artigo tratará da relação literatura infantojuvenil, mediador de leitura e leitor, e cultura de massa, a partir de fundamentação teórica de Borelli (1996), Ceccantini $(2006,2011)$, Eco $(1985,2001)$ e Lajolo (2002). Assim, essa relação será demonstrada com base na obra infantojuvenil $A$ grande viagem (2006), de Mirna Pinsky - apresentada nesta introdução -, apontando aspectos literários e de cultura de massa que a compõem, e propondo reflexão quanto à contribuição daqueles para a formação do jovem leitor.

\section{Literatura infantojuvenil, mercado e cultura de massa: passagens e empecilhos na trilha do leitor}

O escritor de obras infantojuvenis, em sua preocupação com a formação do jovem leitor, enfrenta, atualmente, exigências no campo da indústria cultural e do mercado editorial, e o desafio de produzir literatura não pré-digerida - ou kitsch, conforme a concepção de Dwight Macdonald (1971) -, porém acessível a seu público leitor, sendo esses requisito quantitativo e responsabilidade qualitativa, respectivamente. João Ceccantini (2006) explica esse embate:

\footnotetext{
Percebe-se que é esse um nó fundamental com que tem de lidar o escritor de literatura juvenil, uma vez que, se moldar sua obra somente segundo concepções temáticas e formais 'elevadas', que busquem a aproximação com o centro - ou o 'coração'- do sistema literário, aspirando a integrarse ao cânon, corre o sério risco de perder seus leitores, ainda em franco processo de desenvolvimento. Se o escritor, por outro lado, entregar-se apenas às demandas do coração dos leitores, corre o risco de fazer exclusivamente o jogo do mercado e da indústria cultural, abrindo mão de metas consistentes e produzindo somente 'mais do mesmo', num progressivo afastamento do universo da arte $\mathrm{e}$ da literatura. (CECCANTINI, 2006, p. 121-22)
} 
Embora argumentos histórico-sociais apontem para que a cultura de massa seja democrática e crie possibilidades de "fruição de experiências ordem superior" (ECO, 2001, p. 39), deve-se considerar que essa possa produzir, ainda, efeito facilitador e de passividade e conformismo sobre o fruidor (ECO, 2001, p. 41-42). Em se tratando de literatura infantojuvenil - que se insere na subcategoria literatura de entretenimento, segundo José Paulo Paes (PAES, 1990, p. 28 apud BORELLI, 1996, p. 44) -, uma obra que se comprometa a oferecer algo novo e desafiador ao leitor pode, por sua vez, elevar suas preferências e transformar sua visão de mundo. Ceccantini (2011) orienta para que os mediadores de leitura, isto é, escritores, editores, professores e pais, não se satisfaçam:

(...) com textos banais, didatizados, simplificadores, feitos de encomenda pelo mercado para atender a esta ou aquela faixa etária, a esta ou aquela série escolar, a este ou aquele tema da moda, por inserir-se nas diretrizes educacionais A, B ou C. É preciso não ter medo de colocar nas mãos das crianças, o quanto antes, textos literários densos, de maior complexidade, de ampla envergadura, textos cuja leitura deixe marcas profundas na personalidade de quem os lê. (CECCANTINI, 2011, p. 119, grifo nosso)

No Pós-escrito a O Nome da Rosa (Nova Fronteira, 1985), Umberto Eco destaca que, durante o processo criativo, se possa construir, "através do texto, um modelo específico de leitor" (ECO, 1985, p. 41), sem o interesse de "ir ao encontro dos desejos dos leitores tais como eles são" (ECO, 1985, p. 42), para, que, então, esse novo leitor seja revelado "a si próprio". Desse modo, mostra-se arbitrária a unanimidade quanto a uma classificação marginal para a literatura infantojuvenil, em cuja área muitos trabalham para a formação de novos leitores por meio de produções e indicações - no caso dos que em ambiente escolar - que contestem a corrente mercadológica, ainda que inseridos nesse contexto; e inadequada a concepção do jovem leitor como não indivíduo, dado que tais esforços se voltam àquele, que, por outro lado, se revela a si mesmo. Marisa Lajolo (2002) observa a posição do mediador diante desse cenário:

$\mathrm{E}$, porque somos (...) avalistas, arautos, mediadores e intermediários dos textos que almejam circular na escola e nos seus arredores, transformamo-nos em alvo dos que pretendem as mãos, os olhos e os bolsos das crianças e jovens já igualmente desindividualizados na categoria leitores-de-livros-infantis-ou-juvenis, que aguardam de nossas recomendações oficiais e conversas oficiosas o sinal verde. Sinal que Revista de Letras JUÇARA, Caxias - Maranhão, v. 03, n. 01, p. 51 - 64, ago. 2019 | 53 
também aguardam crianças, jovens e mestres de ambos para que, lendo tais livros, sagrem-se leitores... (LAJOLO, 2002, p. 37, grifo da autora)

Em contrapartida, uma obra facilitadora não contribui à longa e progressiva jornada de leitura, isto é, a formação de crianças e jovens, visto que a abordagem dos temas seria superficial. Ceccantini (2011) esclarece:

\begin{abstract}
Por oposição, quando submetemos a essas exigências muitas obras que circulam hoje, com a ambição de tratar de "questões psicológicas" da criança, conhecidas no meio editorial como "comportamentais", fica patente que não resistem a uma análise mais cuidadosa. Medo de escuro, xixi na cama, primeiro dente que vai cair, irmãozinho que vai nascer, perda de um ente querido, pelinhos que começam a nascer, entre tantos outros temas demandados pelo mercado, são tratados de modo explícito, no nível manifesto, em histórias feitas de encomenda, quase sempre muito artificiais. São exceções as histórias que conseguem dar a esses temas tratamento ficcional minimamente consistente e aceitável. No geral, são histórias de tosca carpintaria literária, que pouco estimulam a imaginação e pouco exigem do intelecto. Se a criança que lê não estiver vivenciando naquele momento a questão focalizada pela história, dificilmente terá seu interesse despertado pelo texto, que parecerá tolo e banal, fadado ao esquecimento. (CECCANTINI, 2011, p. 124, grifos nossos)
\end{abstract}

Dessa maneira, não haveria a construção do leitor, que, por consequência, não descobre nem desenvolve sua individualidade, comprometendo essa jornada.

Por outro lado, seria equivocado ignorar a presença e provável contribuição da cultura de massa no meio literário, embora se afirmem efeitos negativos da cultura de massa sobre o leitor - como o facilitador e de passividade. Silvia Borelli (1996, p. 45) sustenta que "consolidar outras histórias literárias pressupõe confirmar a articulação entre matrizes populares, manifestações da cultura de massa e elementos da cultura erudita", e que "a persistência na recusa e na negação só tende a estrangular e empobrecer a reflexão sobre o papel da cultura e da literatura em sociedades modernas" (BORELLI, 1996, p. 48). Desse modo, a estudiosa sugere que se considere uma reflexão que compreenda os "mecanismos de constituição" (BORELLI, 1996, p. 51), como "produção, circulação, gêneros, consumo, recepção", do produto, o qual seria manifestação literária e cultural.

Devido à modernização, que, como vimos, também propiciou a democratização das sociedades, essas mantêm contato com informação excessiva - argumento de acusação à cultura de massa. Eco (2001, p. 46), por sua vez,

Revista de Letras JUÇARA, Caxias - Maranhão, v. 03, n. 01, p. 51 - 64, ago. 2019 | 54 
defende, em harmonia com a concepção hegeliana, que o "acúmulo de dados quantitativos [...] possa resolver-se, para algumas [pessoas], em mutação qualitativa", e que "só aceitando a visão dos vários níveis como complementares e todos eles fruíveis pela mesma comunidade de fruidores, é que se pode abrir caminho para uma melhoria cultural dos mass media" (ECO, 2001, p. 59). Nesse sentido, presume-se a oportunidade de acesso ao livro, a literaturas de formação e, ainda, à literatura canônica. Por isso, urge que o mediador saiba dosar suas escolhas - de produção ou seleção -, isto é, garantir um "equilíbrio difícil" (LAJOLO, 2002, p. 107), de modo que o leitor não prove a mesma qualidade de obra somente, tornando suas experiências de leitura automatizadas, ou alguma que se mostre inadequada a seu estágio, impossibilitando, também, seu progresso. Logo, uma vez que podem auxiliar no contato com a leitura e, ainda, nessa transição, os elementos da cultura de massa não deveriam fazer-se inexistentes no meio literário. Borelli (1996) descreve esse processo:

\begin{abstract}
As sociedades modernizam-se, a cultura internacionaliza-se e as antigas perspectivas exaltadoras do nacional contra o estrangeiro, do popular versus o erudito, do local obstáculo ao global cedem lugar a um tipo de reflexão sobre cultura que tenta dar conta das diversidades, particularidades, localidades, sem perder de vista os processos mais gerais de globalização e internacionalização da cultura, sem perder a noção e o sentido de que se vive um amplo movimento denominado, na precisa conceituação moriniana, planetarização da cultura ${ }^{5}$. (BORELLI, 1996, p. 51, grifo da autora)
\end{abstract}

Assim, devem-se considerar os estágios de formação do jovem leitor individualizado, a dedicação de mediadores interessados por aquela, o abandono da concepção inferiorizada quanto à categoria literatura infantojuvenil - que não somente de literatura de entretenimento -, e a conciliação entre arte e cultura de massa para a concretização da primeira, a qual, segundo Lajolo (2002, p. 106), favorece a experiência pessoal de cada leitor de modo a esse exercer cidadania nessa complexa sociedade industrial e acumular significados em sua caminhada.

\title{
A grande viagem: alargando os passos do jovem leitor
}

\footnotetext{
${ }^{5}$ Referência ao termo de Edgar Morin (1977).

Revista de Letras JUÇARA, Caxias - Maranhão, v. 03, n. 01, p. 51 - 64, ago. 2019 | 55
} 
A grande viagem (Mercuryo Jovem, 2006), de Mirna Pisnky, editada por Ione Meloni Nassar, e selecionada e adquirida pelo Programa de Bibliotecas da Secretaria da Educação do Estado de Goiás ${ }^{6}$, retrata as dificuldades encontradas por Marcelo em face do divórcio de seus pais, o novo emprego da mãe em condições precár a educação e a saúde de seus irmãos comprometidas, envolvimento com drogas, e o acompanhamento psicológico a ele oferecido por Nara, que tenta confrontar suas atitudes e incentivá-lo na busca por soluções; a obra acompanha, ainda, os desafios de Mercedes quanto à sua família, rendimento escolar, drogas e autoestima, relatados à sua prima mais velha, Daniela, via e-mail e, posteriormente, compartilhados com sua avó. Dessa forma, mediante três vozes narrativas que se intercalam ao longo de capítulos organizados de forma não linear (sessões de terapia, experiências familiares e e-mails), $A$ grande viagem explora essas questões a fim de que sejam elucidadas e não tomadas como destino final de cada personagem.

O livro apresenta, exteriormente, orelha com a formação, livros, prêmios, iniciativas sociais e contato da autora; ilustração de Cesar Landucci ${ }^{7}$, em que se veem um relógio, na parte superior da capa - possivelmente, o passar do tempo na vida das personagens, que precisam de soluções imediatas -, e um lápis escolar, uma bicicleta e uma chave, centralizados na inferior - sugerindo, segundo a obra, a importância da escrita na vida das personagens, e sua viagem, que, por sua vez, pode surtir como prisão ou liberdade, dependendo de suas escolhas; título com destaque à letra e de "viagem", em forma de número "3" (três), que revelaria as três vozes que conduzem a narrativa da obra, "ampliando o campo de visão" e conferindo-Ihe agilidade (PINSKY, 2011, n.p.); e, além disso, sumário que intercalem as três vozes: capítulos com intervalos semanais, entre "20 de maio" e "10 de julho", relatam as sessões de Marcelo e Nara; capítulos "Sair voando" remetem a experiências com drogas e pensamentos desorganizados de Marcelo e/ou Mercedes; e, por fim, capítulos "Mercedes", que enfocam os conflitos da adolescente.

\footnotetext{
6 Disponível em: <http://mercuryojovem.com.br/a-grande-viagem>. Acesso em: 15 fev. 2018.

7 Recebeu o Prêmio Jabuti, na categoria Melhor Projeto Gráfico, em 1992, pelo projeto gráfico da coleção Acorda, Bicho- homem.

Revista de Letras JUÇARA, Caxias - Maranhão, v. 03, n. 01, p. 51 - 64, ago. 2019 | 56
} 
Por meio de diálogos rápidos, linguagem cotidiana e descrições ou reflexões de narrador em primeira ou terceira pessoa, A grande viagem, de Mirna Pinsky, aproxima o jovem leitor à realidade das personagens. No primeiro capítulo, por exemplo, observamos o olhar de Nara - psicóloga de Marcelo - sobre seu paciente:

Cabelo arrepiado com gel, camiseta cinco números maior que o corpo, brinco na orelha direita, e eterno ar de tédio. Profundo tédio. Mas com um brilho contagiante no olhar quando quer alguma coisa e decide seduzir a pessoas de quem essa coisa depende. (PINSKY, 2006, p. 7)

A avaliação da psicóloga mescla-se à de um narrador onisciente, que expressa a opinião de Nara quanto à linguagem coloquial de Marcelo ao tratar de temas como drogas - que impede o progresso da viagem do jovem:

- Dona Beatriz trouxe a 'mercadoria' - e a voz de Nara tem aquele tom irônico que ele sempre recebe como ameaça. - E nós examinamos aqui. - E é da boa, não é? - ele ainda tenta ser engraçado.

- Não, NÃO É DAS BOAS! Porcaria legítima. Mas isso tanto faz, você sabe disso. O que importa é, caramba, Marcelo, POR QUÊ? (PINSKY, 2006 , p. 8 , grifos nossos)

No capítulo seguinte, "Sair voando", em que Marcelo tem acesso de raiva devido à presença do pai e às condições a que esse submeteu sua família, o jovem, desorientado devido ao efeito de drogas, mas lúcido quanto ao que o cerca, reflete sobre a vida difícil da mãe, demonstrando consciência em meio a uma vida - e, consequentemente, linguagem - desesperada:

Gosto demais da mãe. A mãe me dá pena. Tipo da pessoa que a vida desperdiçou. Uma cabeça boa, super bom-caráter e uma energia incrível pra ajudar os outros. A vida engoliu a mãe, enterrou-a numa fábrica por oito horas todos os dias - já pensou, oito horas, todo santo dia, tem mais de quatro anos? - costurando varetas de guarda-chuvas! Peças grandes, pequenas, tecidos brancos, pretos, marrons, estampados, tristes, alegres, a vida dela pulando das mãos para as varetas, das varetas para as vitrines, das vitrines, para outras mãos molhadas de chuva. Quando penso no desperdício, fico doido. (PINSKY, 2006, p. 11, grifos nossos) 
À linguagem, acrescentam-se, ainda, os momentos em que Mercedes troca e-mails com sua prima mais velha, Daniela, de modo a compartilhar suas insatisfações, utilizando expressões cotidianas e típicas da internet:

\author{
Para: dada@fafa.com.br \\ De: Mercedes \\ Assunto: Ser imensa \\ Dani, \\ Queria ter paz, entende? Paz! Assim, acordar zen numa manhã de \\ inverno, achando que o dia está com a temperatura certa, que a neblina \\ deixa as coisas com a tonalidade certa, que o buzinaço do trânsito é um \\ ruído melodioso e que esse TÉÉÉÉÉÉDIO perene e horroroso sumiu de \\ vez. \\ $[\ldots]$ \\ Pena, pena, pena que no dia seguinte começa tudo de novo. Tou \\ pensando em jogar uma pedra no espelho do meu quarto, o que acha da \\ idéia? Pelo menos não vai ter uma gordona do outro lado me olhando \\ com cara de profundo tédio toda manhã. (PINSKY, 2006, p. 24-25, grifos \\ nossos)
}

Dessa maneira, o leitor segue diferentes ritmos e situações da narrativa da obra, que se entrecruzam entre si, desafiando-se a compreender essas relações e a organização daquela como um todo, e tornando-se, gradualmente, imerso em realidades que possa conhecer ou não: se sim, poderá deparar-se com outras possibilidades sugeridas ou proporcionadas pelo acesso a essa e outras leituras; se não, estará, ao menos, consciente de que os desafios encontrados por Marcelo e Mercedes possuem raízes profundas e são encarados e compartilhados mediante a viagem, isto é, fuga:

A viagem de Mercedes não está sendo boa como a minha. Ela está muito triste, melancólica. De vez em quando sobe num muro e recita umas quadrinhas infantis. De vez em quando abraça e beija algum desconhecido. Mas age em câmera lenta, como se tivesse muito sono ou estivesse vivendo num sonho. E não estamos? (PINSKY, 2006, p. 50)

No que concerne ao enredo e desenvolvimento da obra e dos personagens, revela-se a influência da terapeuta de Marcelo e da avó de Mercedes sobre os dois adolescentes. Nara procura conhecer, ao longo das sessões, os problemas de Marcelo, e esforça-se para Ihe transmitir o que acredita ser necessário para que o jovem consiga viver em sociedade como participante: "E Nara se vê explicando ao

Revista de Letras JUÇARA, Caxias - Maranhão, v. 03, n. 01, p. 51 - 64, ago. 2019 | 58 
garoto o bê-á-bá da cidadania, aquela coisarada que transforma um bando num grupo organizado" (PINSKY, 2006, p. 31). A terapeuta descobre, ainda, suas aspirações e aflições mais secretas:

- [...] E os trapezistas? O trapézio pra mim é uma mágica. O trapezista é um homem-mágico, que desafia os limites do corpo. O trapezista é um homem que sabe voar. Imagino a sensação de... de...

- De plenitude?

— Isso: plenitude... a sensação de plenitude de alguém lá no alto, sabendo que pode chegar até o outro lado da lona sem contar com as passadas dos pés. É a glória! Ah, se eu pudesse escolher, eu queria ser um trapezista.

- Mas você pode, por que não?

- Porque... porque eu não tenho grana, porque eu preciso encontrar um jeito de ajudar minha irmãzinha doente e meu irmão que não consegue aprender nada, e tem a mãe que está se matando pra ganhar mixaria, e... (PINSKY, 2006, p. 34)

— Um sonho só meu? Meu sonho maior?

— Um sonho, vários sonhos, o que você quiser contar.

- Quero viajar e conhecer tudo.

[...]

- $\mathrm{E}$ o que isso significa para você?

- Que eu tenho um rumo, eu tenho um sentido. Na maior parte do tempo - e isso me dá agonia - sinto que me programaram, entende? Esperam tanta coisa de mim... Acho que esperam... Se realizo, ficam tranqüilos. Se não realizo, vem pauleira de tudo quanto é lado: pai, escola, até a mãe também. Mas o que esperam de mim não me dá o menor tesão. (PINSKY, 2006, p. 47)

Só sei que fazia tudo com muita intensidade e agora está difícil de me entregar pra alguma coisa qualquer que me dê o mesmo prazer. Parece que estou sendo empurrado para dentro de uma máquina que vai me engolir, me deglutir e depois me cuspir feito um inseto. E um dia eu acordo barata ${ }^{8}$. (PINSKY, 2006, p. 62)

Nesse sentido, Nara desempenha, na jornada de Marcelo, o papel de conhecê-lo para que possa lhe indicar um caminho por que seguir - superando conflitos distante das drogas.

O mesmo se dá com a avó de Mercedes: inserida no meio digital, após a troca de alguns e-mails com sua prima, a adolescente conclui que deve dedicar algum tempo à avó Maristela, evitando aborrecimentos na casa de seus pais; aquela, por sua vez, insiste em que explorem sua Bat-biblioteca e façam planos

${ }^{8}$ Alusão à novela $A$ Metamorfose (1915), de Franz Kafka.

Revista de Letras JUÇARA, Caxias - Maranhão, v. 03, n. 01, p. 51 - 64, ago. 2019 | 59 
culturais juntas. A princípio, a ideia não agrada a Mercedes, porém seu desgosto mantém raízes em problemas com relações familiares e na falta de autoestima:

\begin{abstract}
Não estava nos planos de Mercedes fazer um programa de avó. A verdade é que a aflição que sentia não iria caber numa sala fechada, muito menos na tranqüilidade da leitura de um livro. Fazia tempo que ler deixara de ser uma coisa divertida. [...] Nessa época, a biblioteca de vó Maristela era um jardim encantado. Cada livro, uma história para ela viver. [...] Mas um dia deu um estalo - ela não se lembra como - e começou a ver que imenso tédio era de fato sua vida. Olhou para os pais e viu duas pessoas que falavam uma língua estranha. $E$ foi aí que tudo começou a desandar. (PINSKY, 2006, p. 54-55)

Deu de engordar. Sem mais aquela, começou a perder roupas. Não cabia em mais nada. [...] Esse foi o primeiro baque. [...] O rosto ficara rechonchudo com bochechas que ela não tinha desde pequena. [...] Nada ficava bom. Com ou sem batom. Com ou sem lápis realçando os olhos verdes que um dia mereceram um poema - super kitsch ${ }^{9}$, mas simpático - de um fã colega de classe. (PINSKY, 2006, p. 55, grifo nosso)
\end{abstract}

Antes de contatar a avó, Mercedes demonstra apreciar, contudo, a música - há referências de Skank e Barão Vermelho a Elis Regina, Tom Jobim e Chico Buarque - e, especificamente, o canto:

\begin{abstract}
Mercedes ama CANTAR. E cantando é o melhor jeito que conhece de aquietar a aflição. Então se põe a baixar as músicas para o seu computador e solta a voz. A linda voz com registro de contralto e afinação espontânea, que desde criança lhe garantiram um lugar de destaque no coral da escola. (PINSKY, 2006, p. 26)
\end{abstract}

\begin{abstract}
Mercedes não entende, não entende mesmo, por que a mãe encrenca tanto quando ela coloca a Mônica Salmaso ${ }^{10}$ no som e se põe a fazer a segunda voz, bem mais baixa do que a da cantora e depois atravessa e cantarola em falsete. Não pode ser só por causa das sofríveis notas em geografia, história, ciências e matemática (...). (PINSKY, 2006, p. 26)
\end{abstract}

Conciliados os gostos de ambas e após uma noite no Sesc e em um bar com karaokê, a aproximação entre as personagens surte positivamente sobre Mercedes, isto é, a garota pode compartilhar seu "desconforto e total desamparo" (PINSKY, 2006, p. 80) de modo a ser acolhida pela avó.

\footnotetext{
9 Termo de Macdonald (1971), explicado no subitem anterior.

10 Voadeira (1999), o título de um dos álbuns de Mônica Salmaso, remete aos capítulos "Sair voando" da obra e à busca de Mercedes quanto a "aquietar a aflição".
}

Revista de Letras JUÇARA, Caxias - Maranhão, v. 03, n. 01, p. 51 - 64, ago. 2019 | 60 
Por consequência, os dois jovens percebem a urgência de novos rumos, como expressa Marcelo em dois diferentes momentos: "Preciso urgentemente, encontrar a minha trilha. E não é andando em ônibus fedidos e vendendo revista de mulher pelada pra neuróticos espinhudos, que ela vai aparecer" (PINKSY, 2006, p. 76), e "Ah! se eu pudesse estancar esse momento! O que eu daria para poder voar por todo o sempre!" (PINSKY, 2006, p. 73). A alternativa encontrada por Marcelo, então sugerida a Mercedes, é a escrita ou "relato de viagem":

Começa a ser construído, pelo milagre da palavra, na busca comum por um espaço sem dúvidas, medos, inseguranças e dor, o vínculo até então anestesiado.

- E esse manuscrito, Marcelo... - diz Mercedes, abrindo o pacote de folhas brancas com vinte e tantas páginas manuscritas.

- É o meu relato. É a minha viagem.

- Hummm. "Sair voando", é... a gente queria mesmo isso: sair voando...

- Estive pensando umas coisas, Mercê. Por que você não bota também no papel o teu vôo? Senta e escreve. A minha história ficou sem final. Deixei pra escrever isso junto com você. Depois. O que acha?

- É... não tinha pensado em escrever... mas talvez... Nesses últimos tempos venho tentando encarar o que aconteceu, como uma preparação. Tenho pensado muito. Desse jeito não dá mais. [...]

- Fica com a pasta. Se achar legal minha sugestão, faça também seu exorcismo por escrito. Não sei aonde vou chegar, mas está na hora de seguir em frente, passar para outra. Vou batalhar uma viagem diferente. Uma Grande Viagem. Vou botar todas minhas fichas nela. Vou dar um tempo pro faz-de-conta. Xôooo. (PINSKY, 2006, p. 85-86)

Logo, por meio de três vozes narrativas - de Marcelo, Nara e Mercedes -, a representação de diferentes situações que se podem fazer presentes na vida de um adolescente - questões domésticas, acompanhamento psicológico, relacionamentos via redes sociais, falta de incentivo à leitura e envolvimento com drogas -, o entrelaçamento dessas situações de modo não linear - representando a confusão vivida pelos personagens -, e a sugestão de elementos literários e culturais, a obra se desenvolve formal, estilística, temática e funcionalmente: buscam-se caminhos e soluções aos problemas familiares e pessoais de Marcelo e Mercedes, e trilhas para sua Grande Viagem como indivíduos e cidadãos; e apresentam-se, enfim, desafios de leitura, que contribuem à formação do leitor. 


\section{Considerações finais}

A partir de breve exposição de A Grande Viagem - personagens, enredo, linguagem e temática -, devem-se enfatizar, por fim, os aspectos de sua produção em relação à indústria cultural, com base nas "peças de acusação" àquela - cultura de massa -, identificadas por Umberto Eco (2001, p. 39), e a composição da obra infantojuvenil, de modo a evidenciar seu caráter artístico ou mercadológico, ou ambos.

Embora muitas sejam contestadas, ressaltam-se as seguintes alegações quanto: a "lei da oferta e da procura" (ECO, 2001, p. 40) no circuito comercial, que, em se tratando de um livro para um público leitor jovem, se volta às bibliotecas escolares, como se deu com A Grande Viagem, pelo Programa de Bibliotecas da Secretaria da Educação do Estado de Goiás; a diluição e facilitação dos conteúdos, diferentemente da organização do livro de Mirna Pinsky, que, por sua vez, confunde as vozes narrativas e a realidade das personagens; a universalização dos indivíduos, que se dá pela fácil identificação do leitor para com as personagens, como Marcelo e Mercedes e seus problemas familiares e de autoestima, e envolvimento com drogas; o encorajamento de "uma visão passiva e acrítica do mundo" (ECO, 2001, p. 41), não aceita pelas personagens da obra, especialmente por Marcelo no que concerne a sua família - isto é, o trabalho penoso da mãe e a dificuldade do irmão nos estudos; o conformismo "no campo dos costumes, dos valores culturais, dos princípios sociais e religiosos, das tendências políticas" (ECO, 2001, p. 42), que não é incentivado por Nara e a avó Maristela quanto aos dois adolescentes, de modo a esses optarem por mudanças; e o mascaramento da diversidade cultural e social (ECO, 2001, p. 43), não aderido pela obra na representação da vida de Marcelo e de seus contextos familiar e escolar.

Portanto, percebe-se relação entre $A$ Grande Viagem, cultura de massa e mercado - devido aos elementos indicados na obra, como universalização das personagens, representação de contato pela internet e referências a produtos culturais -, e, ainda, a formação do jovem leitor, já que proporciona leitura desafiadora ao público consumidor, por meio da falta de linearidade, linguagem diversa, pluralidade de vozes e referências literárias e culturais. Essa relação dual, entretanto, não parece comprometer a natureza literária da obra nem a função e o 
compromisso da escritora em "ser os caminhos de formação e salvação" (ECO, 2001, p. 38) mediante a "individuação desses caminhos" (ECO, 2001, p. 39), a ser trilhados pelo leitor.

\title{
ART AND MASS CULTURE IN A GRANDE VIAGEM BY MIRNA PINSKY
}

\begin{abstract}
The aim of this article is to address literary and mass culture aspects in children's book $A$ Grande Viagem (2006) by Mirna Pinsky, which depicts Marcelo and Mercedes's challenges amid drugs and low self-esteem by way of three narrative voices, nonlinearity and literary and cultural references. By using theoretical basis of Borelli (1996), Ceccantini $(2006,2011)$, Eco $(1985,2001)$ and Lajolo (2002), who enable considerations regarding entertaining literature in relation to cultural industry and canon, and the function of the reading mediator, it is thus demonstrated that Pinsky's work offers to the reader a new perspective on what concerns the characters' reality and their social context, and, although inserted in a market circuit, may assume literary quality.
\end{abstract}

Keywords: Children's literature. Literary reception. Cultural industry.

\section{Referências}

A GRANDE VIAGEM. Disponível em: <http://mercuryojovem.com.br/a-grandeviagem>. Acesso em: 15 fev. 2018.

BORELLI, Silvia Helena Simões. Literatura, literaturas. In: Ação, suspense, emoção: Literatura e cultura de massa no Brasil. São Paulo: EDUC; Estação Liberdade, 1996. p. 23-53.

CECCANTINI, João Luís Cardoso Tápias. A marca de uma lágrima de Pedro Bandeira: entre o coração dos leitores e o da literatura. In: AGUIAR, Vera T.; MARTHA, Áurea P. (org). Territórios da Leitura: da literatura aos leitores. São Paulo: Cultura Acadêmica, 2006.

. Literatura infantil: a narrativa. In: UNIVERSIDADE ESTADUAL PAULISTA. Prograd. Caderno de formação: formação de professores didática geral. São Paulo: Cultura Acadêmica, 2011. v. 11. Disponível em: <http://acervodigital.unesp.br/handle/123456789/40365>. Acesso em: 13 fev. 2018.

ECO, Umberto. Pós-Escrito a O Nome da Rosa. Rio de Janeiro: Nova Fronteira, 1985.

. Cultura de massa e "níveis" de cultura. In: Apocalípticos e integrados. São Paulo: Perspectiva, 2001. p. 33-67.

LAJOLO, Marisa. O mundo da leitura para a leitura do mundo. São Paulo: Ática, 2002.

MACDONALD, Dwight. Massicultura e medicultura. In: ECO, Umberto et al. $A$ indústria da Cultura. Lisboa: Meridiano, 1971. p. 67-149.

MIRNA PINSKY. Disponível em: <http://mirnapinsky.com.br/>. Acesso em: 09 fev. de 2018.

Revista de Letras JUÇARA, Caxias - Maranhão, v. 03, n. 01, p. 51 - 64, ago. 2019 | 63 
MORIN, Edgar. A integração cultural. In: Cultura de massas no século XX: o espírito do tempo - I: neurose. Rio de Janeiro: Forense Universitária, 1977, p. 11-85.

PAES, José Paulo. A aventura literária. São Paulo: Companhia das Letras, 1990, p. 28. In: BORELLI, Silvia Helena Simões. "Literatura, literaturas". In: Ação, suspense, emoção: Literatura e cultura de massa no Brasil. São Paulo: EDUC; Estação Liberdade, 1996, p. 23-53.

PINSKY, Mirna. A grande viagem. São Paulo: Mercuryo Jovem, 2006.

A leitura na construção da criança. 2009. Disponível em: <http://mirnapinsky.com.br/artigos/>. Acesso em: 16 fev. 2018.

Conversa sobre criação. 2011. Disponível em: <http://mirnapinsky.com.br/artigos/>. Acesso em: 15 fev. 2018. 